SCIENTIFIC REPORT

\title{
The usefulness of Vistech and FACT contrast sensitivity charts for cataract and refractive surgery outcomes research
}

\author{
K Pesudovs, C A Hazel, R M L Doran, D B Elliott
}

Br J Ophthalmol 2004;88:11-16

\begin{abstract}
Aim: To investigate the repeatability and sensitivity of two commonly used sine wave patch charts for contrast sensitivity (CS) measurement in cataract and refractive surgery outcomes.

Methods: The Vistech CS chart and its descendant, the Functional Acuity Contrast Test (FACT), were administered in three experiments: (1) Post-LASIK and age matched normal subjects; (2) Preoperative cataract surgery and age matched normal subjects; (3) Test-retest repeatability data in normal subjects.

Results: Contrast sensitivity was similar between post-LASIK and control groups and between the Vistech and FACT charts. The percentage of subjects one month post-LASIK achieving the maximum score across spatial frequencies $(1.5,3,6,12,18$ cycles per degree) were $(50,33,13,13,0$ respectively) for $\mathrm{FACT}$, but only $(0,0,13,4,0$ respectively) for Vistech. A small number of cataract patients also registered the maximum score on the FACT, but up to $60 \%$ did not achieve the minimum score. Test-retest intraclass correlation coefficients varied from 0.28 to 0.64 for Vistech and 0.18 to 0.45 for FACT. Bland-Altman limits of agreement across spatial frequencies were between \pm 0.30 and $\pm 0.85 \log C S$ for Vistech, and \pm 0.30 to $\pm 0.75 \log C S$ for FACT.

Discussion: The Vistech was confirmed as providing poorly repeatable data. The FACT chart, likely because of a smaller step size, showed slightly better retest agreement. However, the reduced range of scores on the chart due to the smaller step size led to ceiling (post-LASIK) and floor (cataract) effects. These problems could mask subtle differences between groups of patients with near normal visual function as found post-refractive or cataract surgery. The Vistech and FACT CS charts are ill suited for refractive or cataract surgery outcomes research.
\end{abstract}

M uch has been written about the inadequacy of visual acuity (VA) as the sole measure of visual performance after refractive and cataract surgery and the need to measure visual outcome in terms of contrast vision. ${ }^{1-8}$ This is gaining acceptance and many refractive surgery studies have included a measure of vision in the contrast domain-either contrast sensitivity (CS), ${ }^{9-16}$ or low contrast visual acuity (LCVA). ${ }^{17-20}$ Many cataract surgery outcome studies have also included a measure in the contrast domain. ${ }^{21-26}$ However, what is less accepted is which tests of CS are best suited to such outcomes studies.

There are several commercially available clinical tests that measure CS, but the most commonly used are the Vistech in its various versions (including wall charts VCTS 6500 and the vision screener based MCT-8000 $)^{27-29}$ and similar charts such as the Vector Vision CSV-1000. ${ }^{30} 31$ These charts have the advantage over letter CS charts, such as the Pelli-Robson chart, $^{32}$ in that they can measure CS at several spatial frequencies. The Vistech CS chart was first introduced in $1984,{ }^{27}$ and contains circular photographic plates of sine wave gratings arranged in five rows (spatial frequencies 1.5, 3, 6, 12 and 18 cycles per degree $(\mathrm{cpd}))$ and nine columns (contrast levels). The step sizes are irregular, but the average step size is about $0.25 \log$ units with a range of $1.75 \log$ units. The gratings are either vertical or tilted $15^{\circ}$ to the right or left. The patient indicates the orientation of each grating, or responds "blank" if nothing is seen. It is therefore essentially a criterion dependent method as the patient is allowed to decide when they cannot see a grating, and cautious observers may give slightly low CS values. However there is a 3-alternative forced choice (AFC) check on "risk taking" patients as they must indicate the orientation of the gratings. The Vistech charts have been widely used to measure CS in cataract, ${ }^{21}{ }^{23}{ }^{33-37}$ and to assess changes after refractive surgery where they have typically shown no significant decrease in CS. ${ }^{9-11}{ }^{29}{ }^{38-41}$ However, the poor test-retest repeatability of the Vistech charts, ${ }^{42-46}$ could obscure subtle differences between normal and abnormal. The Vistech charts consistently show very poor test-retest correlations of between 0.25 and 0.61 (an average of 0.48$)^{42-46}$

The "second generation" Vistech chart, the Functional Acuity Contrast Test (FACT), ${ }^{47}$ which has also been used in refractive surgery studies, ${ }^{12}{ }^{48-52}$ uses the same format as the Vistech: circular photographic plates arranged in five rows and nine columns; the same spatial frequencies; the same grating orientations. It differs in using smaller step sizes (0.15 log units) and an AFC method, presumably to try to improve repeatability. Given that the number of steps has not changed, a consequence of the smaller step size is a smaller range of scores for the FACT chart compared to the Vistech (Fig 1). It also has "blurred" grating patch edges with the gratings smoothed into a grey background and a larger patch size so that an increased number of cycles are presented at low spatial frequency.

The repeatability and sensitivity of the FACT chart to cataract or refractive surgery changes have not previously been reported, and the chart has not been compared to its predecessor, the Vistech chart. In this study, we assessed the sensitivity of the Vistech and FACT CS charts to changes after refractive surgery (experiment 1 ), assessed the sensitivity of the FACT CS chart in cataract subjects (experiment 2) and compared the test-retest repeatability of the FACT and Vistech charts (experiment 3). In addition, we investigated the clinical usefulness of having CS data from five spatial frequencies using factor analysis.

\section{METHODS}

For all experiments, informed consent was obtained from all subjects after the nature of the study had been fully explained. The tenets of the Declaration of Helsinki were followed and the study gained approval from both the 


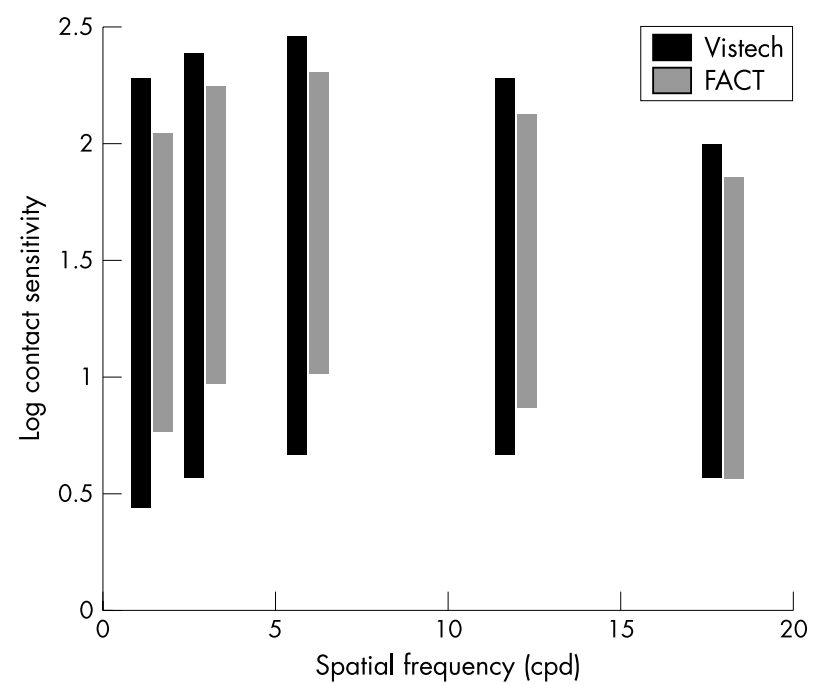

Figure 1 The range of contrast sensitivity over which the Vistech (black columns) and FACT (grey columns) charts can measure.

Bradford University and Leeds Regional Ethical Committees. For experiment 1, inclusion criteria were healthy eyes with a VA better than $0.1 \log$ MAR (6/7.5) for the normal group, and previous LASIK refractive surgery for the refractive surgery group. For experiment 2, inclusion criteria were subjects aged 60 years or older with normal healthy eyes or presenting for cataract surgery (no VA limit); and for experiment 3, inclusion criteria were age 18 years or older with normal healthy eyes and a VA better than 0.1 logMAR (6/7.5). Exclusion criteria were any ocular pathology (other than cataract for the cataract subject group) or abnormality including amblyopia and strabismus; any previous ocular surgery (other than LASIK for the post-LASIK group); any neurological problem, any systemic disease, taking of any medication which may affect contrast sensitivity, inability to speak English sufficiently to be instructed to perform the tests, insufficient mental ability to perform the tests, and physical disability which would make it arduous to perform the tests (for example, wheelchair bound).

\section{Experiment 1}

Contrast sensitivity and VA data were compared between 27 subjects at least five weeks (range 5-64 weeks, mean 22.4 (SD 18.1) weeks) after LASIK surgery (mean age 41.1 (SD 9.8 ) years) and 27 subjects with normal, healthy eyes (mean age 38.8 (SD 9.8) years). Both postoperative and control subjects were recruited from a refractive surgery centre (Ultralase, Leeds, UK). The groups were similar in age $\left(\right.$ ANOVA $\left._{1,52}=0.71, \mathrm{p}=0.40\right)$.

\section{Experiment 2}

Contrast sensitivity (FACT) and VA data were compared between 53 subjects with early cataract (age 73.3 (SD 7.4) years, VA 0.19 (SD 0.23) $\log$ MAR, Snellen 6/9) and 23 subjects with normal, healthy eyes (age 70.3 (SD 4.2), VA -0.03 (SD 0.08) $\log$ MAR, Snellen $6 / 6^{+}$). Cataract subjects were recruited from the ophthalmology pre-assessment clinic of one of the authors (RMLD) at Leeds General Infirmary, Leeds, UK and control subjects were recruited from the Eye Clinic at the University of Bradford. The groups were similar for age (ANOVA $\left.\mathrm{F}_{1,74}=3.40, \mathrm{p}<0.05\right)$.

\section{Experiment 3}

Thirty three subjects with normal, healthy eyes (mean age 31.6 (SD 15.1) years) had CS measurements repeated with a test-retest time of approximately one week. All subjects were recruited from the Eye Clinic at the University of Bradford.

In all experiments, CS was measured with the Vistech and FACT charts using the manufacturer's recommended testing procedure. Measurements were made monocularly with optimal refractive correction and natural pupil, with a chart luminance of $120 \mathrm{~cd} / \mathrm{m}^{2}$ and a working distance of $3 \mathrm{~m}$. The orders of test measurement and of spatial frequency measurement within each test were randomised. With the Vistech chart, the plate furthest along each row correctly seen by each subject determined CS and subjects were allowed to state that they could not see any gratings. As recommended by the manufacturers, a strict 3-AFC measurement paradigm was used with the FACT chart and subjects were forced to guess at a plate that they indicated they could not see. Visual acuity was measured using a Bailey-Lovie logMAR chart with a chart luminance of $160 \mathrm{~cd} / \mathrm{m}^{2}$, a working distance of $4 \mathrm{~m}$ and by-letter scoring.

The data were inspected for compliance with normality and significant differences between the groups were tested with one way analysis of variance (ANOVA). Test-retest reliability was determined by calculating the intraclass correlation coefficient (ICC), and the limits of agreement by the method of Bland and Altman. ${ }^{53}$ Factor analysis was performed to investigate for redundancy within each CS chart. The results from the five spatial frequencies along with VA were included in the analysis with the number of factors (with eigenvalues greater than 1.0) and the correlations taken from the Varimax rotated solution. These analyses were performed on SPSS v 10.1 for Windows (SPSS Inc, Chicago, IL, USA).

\section{RESULTS}

\section{Experiment 1}

The post-LASIK group had slightly worse VA (mean -0.04 (SD 0.08) $\log$ MAR, Snellen $6 / 6^{++}$) compared to the controls $\left(-0.09\right.$ (SD 0.06) $\log$ MAR, Snellen 6/5) $\left(\right.$ ANOVA F $_{1,52}=8.10$, $\mathrm{p}<0.01)$. The mean CS data for both charts and for the postLASIK and control groups are shown in Figure 2. The results from the Vistech and FACT charts were similar (2-factor ANOVA, $p>0.05$ ) within both control and post-LASIK groups, although a significant interaction effect $(\mathrm{p}<0.05)$

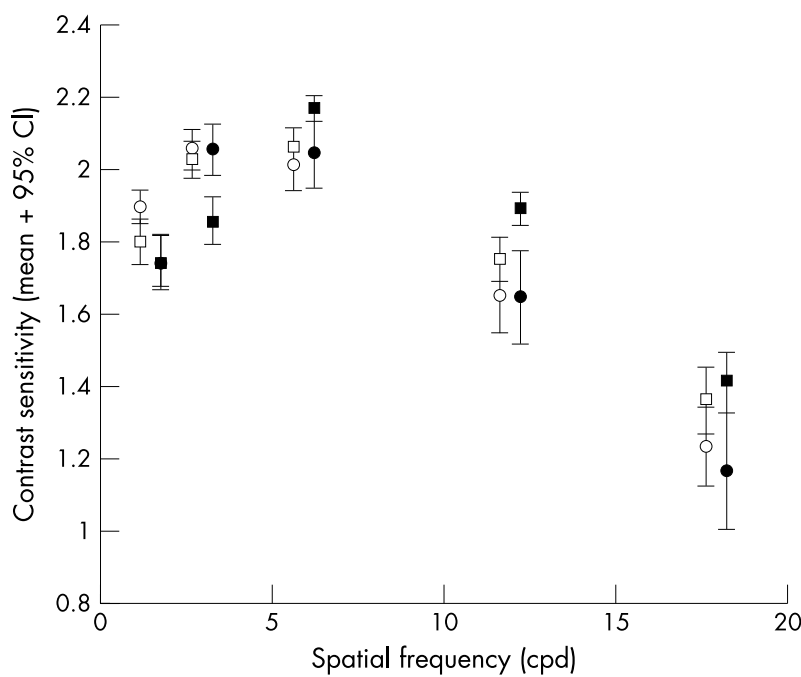

Figure 2 Log contrast sensitivity (mean, 95\% confidence interval) for each of the five spatial frequencies $(1.5,3,6,12,18 \mathrm{cpd})$ of the Vistech and FACT charts. To aid clarity Vistech and FACT data are presented displaced either side of the actual spatial frequency. Data are shown for 27 normal subjects and the 27 post-LASIK subjects. FACT chart=open symbols ( $O$, post-LASIK; $\square$, normal subjects). Vistech = closed symbols (•, post-LASIK; $\mathbf{\square}$, normal subjects). 
indicates that there are some significant differences between the chart scores from individual spatial frequencies. The FACT chart gave average scores higher than the Vistech for 1.5 and $3.0 \mathrm{cpd}$, but lower, or similar, scores for all other spatial frequencies. The post-LASIK group had similar FACT $\mathrm{CS}$ as the controls for all spatial frequencies $(\mathrm{p}>0.05)$ except at $1.5 \mathrm{cpd}(\mathrm{p}<0.05)$ where the LASIK group gave higher CS scores. The Vistech chart found the LASIK group had reduced CS at three spatial frequencies $(\mathrm{p}<0.05)$, and improved CS at one spatial frequency $(\mathrm{p}<0.001)$ compared to the control group.

There was a ceiling effect with many post-LASIK and control subjects scoring the highest CS value possible on the chart for several spatial frequencies. The proportions are listed in table 1. This ceiling effect is much greater on the FACT chart than on the Vistech. To further investigate this ceiling effect, CS was measured, in an additional nine LASIK patients who were seen within one week of surgery (mean age 35.2 (SD 7.4) years, VA - 0.05 (SD 0.05) logMAR, Snellen $\left.\sim 6 / 5^{-1}\right)$. This group were not combined with the longer term follow up group as previous studies have shown larger losses of $\mathrm{CS}$ in the immediate postoperative period, recovering completely or to only subtle losses in the long term..$^{38} 485$ However, the percentage of subjects achieving the maximum score on the FACT were similar to the normal and one month post-LASIK groups (table 1).

Factor analysis of the five CS results for each test and VA yielded two factors for both charts (table 2). The correlations of spatial frequencies and factors show that there is essentially a low spatial frequency factor $(1.5$ and $3.0 \mathrm{cpd})$ and a high spatial frequency factor (VA, 6, 12, and 18) although the $6.0 \mathrm{cpd}$ data for FACT could equally be included in either.

\section{Experiment 2}

The cataract group had poorer FACT CS, at every spatial frequency, than the normal group (ANOVA $F_{1,74}=19.99$ to $44.85, \mathrm{p}<0.001$ ) (table 3 ). This confirms the sensitivity of the FACT to cataract, however the groups were also different in terms of VA (cataract 0.19 (SD 0.23) $\log$ MAR, Snellen 6/9; normal subjects -0.03 (SD 0.08) logMAR, Snellen $6 / 6^{+1}$; ANOVA $\left.F_{1,74}=20.88, p<0.001\right)$. The proportion of cataract and control subjects who achieved the top score for each spatial frequency on the FACT chart are listed in Table 3. The ceiling effect is notable in the normal group, and similar to the normal and LASIK groups from experiment 1 . However, a small ceiling effect also exists in the cataract group (Table 3 ). There is also a large floor effect in the cataract group, especially at higher spatial frequencies, where subjects fail to see the first target and thereby fail to register a score.

\section{Experiment 3}

Vistech and FACT CS were tested twice on a group of 33 normal subjects. There were no significant differences between test and retest for all spatial frequencies $(p>0.05)$. These subjects were younger (mean (SD) age 31.6 (15.1) years) than the groups used in experiments 1 and 2 . The mean $\log$ CS scores are similar to that seen in the normal group in experiment 1 , although slightly better on several spatial frequencies. The repeatability of the CS tests was determined using ICC, the coefficient of repeatability (COR) and the $95 \%$ limits for change (Table 4). The COR, is calculated as 1.96 times the standard deviation of the differences between the test and retest scores. ${ }^{53}$ For measures that use a continuous score, the COR provides a criterion for statistically significant change. For tests that do not measure on a continuous scale, the criterion for significant change falls at the next log CS level above the coefficient of repeatability. Therefore, if the COR was $\pm 0.23 \log$ CS, but the chart used step sizes of $0.10 \log C S$, the criterion for change would be $\pm 0.30 \log$ CS or \pm 3 steps. The $95 \%$ limits of agreement are derived by adding and subtracting the COR from the mean difference. ${ }^{53}$ Due to the coarseness of the step sizes, the practical $95 \%$ limits of agreement would be one log CS step above this figure (Table 4).

\section{DISCUSSION \\ Experiment 1}

The higher CS value at $1.5 \mathrm{cpd}$ on the FACT is likely to be because the low spatial frequency target is larger and thus displays more cycles, which would improve CS. ${ }^{28}$ The Vistech gave higher average readings at all other spatial frequencies probably because the highest CS values attainable on the FACT are lower than those on the Vistech (fig 1, table 1). Therefore a greater proportion of the subjects scored the maximum CS value on the FACT $(42 \%)$ compared with the Vistech $(10 \%)$ (table 1$)$. Even within one week of surgery, when previous studies have shown that the greatest reductions in CS after refractive surgery occur, ${ }^{38} 4854$ at least $33 \%$ showed maximal CS scores at $1.5,3$, and 6 cpd and $11 \%$ at $18 \mathrm{cpd}$. An additional reason why so many subjects scored the maximum on the FACT chart is because a strict 3-AFC method was used as suggested by the manufacturers. This gives a $33 \%$ probability of a subject scoring one step above their threshold due to chance, and an $11 \%$ probability of scoring two steps above threshold.

Although there is a strong ceiling effect with the FACT chart, there is only a minor ceiling effect with the Vistech chart (table 1). It seems that the modification of the first generation Vistech to create the second generation FACT by reduction in step size without an increase in the number of steps has created a FACT chart with a truncated scale (fig l),

Table 1 The maximum log contrast sensitivity score on each of the contrast sensitivity charts and the percentage of the 24 normal subjects, the 27 LASIK subjects, and a further nine LASIK subjects who were tested within the first week after surgery (LASIK 1st week) who achieved that score

\begin{tabular}{|c|c|c|c|c|c|c|c|c|}
\hline & \multicolumn{4}{|l|}{ Vistech } & \multicolumn{4}{|l|}{ FACT } \\
\hline & \multirow[b]{2}{*}{$\begin{array}{l}\text { Maximum } \\
\log \text { CS }\end{array}$} & \multicolumn{3}{|c|}{$\%$ Achieving top score } & \multirow[b]{2}{*}{$\begin{array}{l}\text { Maximum } \\
\log C S\end{array}$} & \multicolumn{3}{|c|}{$\%$ Achieving top score } \\
\hline & & $\begin{array}{l}\text { Normal } \\
\text { subjects }\end{array}$ & LASIK & $\begin{array}{l}\text { LASIK } \\
\text { lst week }\end{array}$ & & $\begin{array}{l}\text { Normal } \\
\text { subjects }\end{array}$ & LASIK & $\begin{array}{l}\text { LASIK } \\
\text { lst week }\end{array}$ \\
\hline $1.5 \mathrm{cpd}$ & 2.23 & 0 & 0 & 0 & 2.00 & 19 & 50 & 33 \\
\hline $3 \mathrm{cpd}$ & 2.34 & 4 & 0 & 0 & 2.20 & 26 & 33 & 44 \\
\hline $6 \mathrm{cpd}$ & 2.41 & 4 & 13 & 0 & 2.26 & 11 & 13 & 33 \\
\hline $12 \mathrm{cpd}$ & 2.23 & 0 & 4 & 0 & 2.08 & 4 & 13 & 0 \\
\hline $18 \mathrm{cpd}$ & 1.95 & 0 & 0 & 0 & 1.81 & 11 & 0 & 11 \\
\hline
\end{tabular}


Table 2 The correlation matrix of the Varimax orthogonal transformation factor analysis including visual acuity and contrast sensitivity results from the Vistech and FACT charts for Experiment 1 data (LASIK and normal subjects) as well as the percentage of the variance explained by each factor

\begin{tabular}{|c|c|c|c|c|c|c|c|}
\hline & $1.5 \mathrm{cpd}$ & $3 \mathrm{cpd}$ & $6 \mathrm{cpd}$ & 12 cpd & $18 \mathrm{cpd}$ & VA & $\begin{array}{l}\text { \% Variance } \\
\text { explained }\end{array}$ \\
\hline \multicolumn{8}{|l|}{ Vistech } \\
\hline Factor 1 & 0.12 & -0.15 & 0.78 & 0.91 & 0.88 & -0.72 & $49 \%$ \\
\hline Factor 2 & 0.85 & 0.83 & 0.37 & 0.01 & 0.00 & 0.16 & $30 \%$ \\
\hline \multicolumn{8}{|l|}{ FACT } \\
\hline Factor 1 & 0.01 & 0.17 & 0.51 & 0.85 & 0.85 & -0.75 & $49 \%$ \\
\hline Factor 2 & 0.81 & 0.89 & 0.58 & 0.29 & 0.10 & 0.10 & $25 \%$ \\
\hline
\end{tabular}

which fails to discriminate between subjects with good contrast sensitivity. So many cases reaching the ceiling of the chart is a serious problem as the FACT chart is missing the most important part of the scale if it were to be used for detecting any subtle loss of CS caused by refractive surgery or, possibly, intraocular lenses.

The advantage of sine wave grating CS tests is that they can measure CS at different spatial frequencies. However, this assumes that CS from neighbouring spatial frequencies provides useful additional information, which may not be the case. ${ }^{42}{ }^{55}$ Principal components factor analysis with Varimax orthogonal transformation indicated that measurements of the grating CS tests can safely be summarised by two scores, one at low spatial frequency and the other at high (Table 2). In addition, VA was also highly covariant with the high spatial frequency factor. This suggests that the two higher spatial frequency results are not necessary as the same information may be more reliably provided by a logMAR VA chart. ${ }^{45} 4656$ Therefore if VA is already reliably measuring the high spatial frequency end of the contrast sensitivity function, all that remains is to measure low spatial frequencies reliably. This could be done with the PelliRobson contrast sensitivity chart, which is sensitive and reliable and free from ceiling and floor effects. ${ }^{32} 454657$ For the Vistech and FACT with superfluous low spatial frequency data, the three lower spatial frequency scores could be considered together to improve reliability and repeatability. In addition, as the grey area on the results sheet represents the $90 \%$ limits of normal, the Vistech or FACT score could be taken to be abnormal if two of the three low frequency scores are below the grey area. $1-(0.95)^{3}=14.3 \%$, so that there is a $2 \%$ probability $(0.143 \times 0.143=0.020)$ that two of the three values will be below the grey area due to chance. ${ }^{55}$ This seems

Table 3 FACT log contrast sensitivity (mean \pm SD), the percentage of the 23 normal subjects and the 53 cataract subjects who achieved the maximum score, the percentage of the cataract subjects who failed to achieve the minimum score, and the minimum measurable FACT scores

\begin{tabular}{|c|c|c|c|c|c|c|}
\hline & \multicolumn{2}{|c|}{$\begin{array}{l}\log C S \\
(\text { mean } \pm S D)\end{array}$} & \multicolumn{2}{|c|}{$\begin{array}{l}\% \text { Achieving top } \\
\text { score }\end{array}$} & \multirow{2}{*}{$\begin{array}{l}\% \text { No } \\
\text { score } \\
\end{array}$} & \multirow{2}{*}{$\begin{array}{l}\text { Minimum } \\
\text { measurable } \\
\text { log CS }\end{array}$} \\
\hline & $\begin{array}{l}\text { Normal } \\
\text { subjects }\end{array}$ & Cataract & $\begin{array}{l}\text { Normal } \\
\text { subjects }\end{array}$ & Cataract & & \\
\hline $\begin{array}{l}1.5 \\
\text { cpd }\end{array}$ & 1.86 & 1.56 & 44 & 4 & 2 & 0.80 \\
\hline $3 \mathrm{cpd}$ & 1.97 & 1.58 & 17 & 0 & 4 & 1.00 \\
\hline $6 \mathrm{cpd}$ & 1.95 & 1.26 & 0 & 2 & 21 & 1.05 \\
\hline $12 \mathrm{cpd}$ & 1.64 & 0.76 & 4 & 0 & 45 & 0.90 \\
\hline $18 \mathrm{cpd}$ & 1.18 & 0.40 & 4 & 0 & 60 & 0.60 \\
\hline
\end{tabular}

to be an acceptable level of false positive results as most charts give the 2.5 th percentile as the lower limit of normal.

\section{Experiment 2}

The FACT chart is sensitive to the presence of early cataract in that depressed scores are seen in the cataract group compared with the normal group. However, ceiling and floor effects hamper accurate measurement of CS in cataract subjects. A strong ceiling effect is seen in the normal group, similar to that seen in normal subjects in Experiment 1, but a weak ceiling effect is even seen in the cataract group. At least two of 53 subjects, who were scheduled for cataract surgery, had contrast sensitivity at two spatial frequencies that was better than that which could be measured with the FACT chart. The strong floor effect with early cataract subjects does indicate that many of them have very poor CS, which is in line with previous studies, and may be clinically useful. ${ }^{58}$ However, their actual CS is not measured, a score of zero is assigned when their true CS falls somewhere within a one log unit range from zero to the minimum possible score (0.60-1.05 log CS depending upon spatial frequency) (fig l, table 4). This has implications for research if a mean score were required, as true CS will be underestimated if a zero score is assigned or overestimated if missing data is assigned. Therefore the FACT chart is missing the most important part of the scale for differentiating patients with loss of CS due to cataract, and as such is a poor test for research in subjects with cataract or other eye diseases causing severe losses of CS.

\section{Experiment 3}

There were no significant differences between mean test and retest scores (table 4), as would be expected if there were no significant training or fatigue effect. The poor reliability of Vistech CS chart measurements was indicated by the low ICCs, which ranged between 0.28 and 0.64 (table 4). Previous studies have also found low test-retest correlations of between 0.25 and $0.61 . .^{42-46}$ Poor repeatability was also illustrated with coefficients of repeatability between \pm 0.26 and \pm 0.54 . Similar values of repeatability have been found previously. ${ }^{44} 46$ This is probably because the Vistech uses large step sizes $(\sim 0.25 \log$ units $)$, a small number of decisions at each level (one), a criterion dependent method and a low number of alternatives (three) to catch risk takers. ${ }^{44} 46$

The FACT chart uses a smaller step size $(0.15 \log$ units $)$ and a fully forced choice method, but the average test-retest ICC is similar to or worse than the Vistech $(0.34 v .0 .46$ respectively) and the average COR is only slightly better $( \pm 0.35 v \pm 0.40 \log$ CS respectively). The poor ICC values may be because of the truncated nature of the FACT data. Many of the scores are at the maximum value (particularly at $1.5 \mathrm{cpd}$ ), so the score is very poor at discriminating between subjects. The retest agreement of the FACT chart is better (95\% limits for change average of $\pm 0.42 \log$ CS for the FACT, 
Table 4 Mean and standard deviation (SD) contrast sensitivities, intraclass correlation coefficients (ICC), coefficient of repeatability (COR), and the $95 \%$ limits for change calculated from test and retest data from 33 normal subjects

\begin{tabular}{llllll}
\hline & $\begin{array}{l}\text { Test (mean } \\
\text { (SD)) }\end{array}$ & $\begin{array}{l}\text { Retest (mean } \\
\text { (SD)) }\end{array}$ & ICC & COR & 95\% limits for change \\
\hline Vistech 1.5 cpd & $1.90(0.21)$ & $1.90(0.17)$ & 0.28 & \pm 0.45 & \pm 0.75 \\
Vistech 3 cpd & $2.17(0.17)$ & $2.22(0.14)$ & 0.37 & \pm 0.33 & \pm 0.42 \\
Vistech 6 cpd & $2.21(0.15)$ & $2.20(0.17)$ & 0.64 & \pm 0.26 & \pm 0.30 \\
Vistech 12 cpd & $1.93(0.23)$ & $1.95(0.25)$ & 0.52 & \pm 0.44 & \pm 0.55 \\
Vistech 18 cpd & $1.49(0.31)$ & $1.47(0.29)$ & 0.49 & \pm 0.54 & \pm 0.85 \\
FACT 1.5 cpd & $1.94(0.12)$ & $1.97(0.07)$ & 0.18 & \pm 0.25 & \pm 0.30 \\
FACT 3 cpd & $2.11(0.11)$ & $2.12(0.12)$ & 0.28 & \pm 0.22 & \pm 0.30 \\
FACT 6 cpd & $2.12(0.11)$ & $2.12(0.10)$ & 0.44 & \pm 0.25 & \pm 0.30 \\
FACT 12 cpd & $1.88(0.22)$ & $1.86(0.19)$ & 0.36 & \pm 0.45 & \pm 0.45 \\
FACT 18 cpd & $1.49(0.26)$ & $1.52(0.26)$ & 0.45 & \pm 0.60 & \pm 0.75 \\
\hline & & & & & \\
\hline
\end{tabular}

compared with $\pm 0.57 \log$ CS for Vistech) probably due to the smaller step size used on the FACT chart ( 0.15 compared to an average of $0.25 \log$ CS). As poor as these reliabilities are, they may overestimate reliability for older (such as cataract) subjects, as it has been previously shown that older subjects have greater variability. ${ }^{46}$

It may be that using the FACT in forced choice mode may not be the best approach. Forced choice tests must contain a large number of trials, otherwise their reliability will be poor. ${ }^{59}{ }^{60}$ In the 3 -AFC mode, the FACT offers a $33 \%$ chance of correctly identifying the grating position with your eyes closed. It may be that, given the design of the FACT with one decision per level and only three alternatives, allowing the patient to respond that they cannot see a grating is preferable. Although when it is used in this manner it is criterion dependent as cautious subjects can set a lower criterion for threshold, the technique still provides a 3-AFC check on risk takers. It may also provide less truncated data, as fewer subjects might reach a maximum score. The CSV$1000^{30} 31$ has also been used in refractive surgery studies. $^{38} 49$ 61-66 Its psychophysical design with one decision per level, a criterion dependent method with a 2-AFC check on risk takers, and a relatively small step size of about $0.16 \mathrm{log}$ units, would suggest its repeatability should be similar to that of the FACT. The Pelli-Robson CS chart or VA charts using Bailey-Lovie LogMAR design features, with three or five decisions per level, approximately 10 (or 26) alternative choices, and a step size of 0.15 or $0.10 \log$ units have both been shown to provide more repeatable measurements of CS or low contrast VA. ${ }^{45} 46$

These reliability data must influence the way any differences in results in experiments are interpreted. The LASIK subjects appear to have lower contrast sensitivity at three spatial frequencies, and higher at one spatial frequency than the normal subjects on the Vistech chart but no differences on the FACT chart (fig 2). A sample size calculation based on the differences between normal and LASIK subjects (accounting for unequal variance between groups), for a power of 0.80 , a type I error rate of 0.05 , an alpha of 0.05 , moderated by repeatability ( sample size divided by ICC) gave minimum sample sizes of ( $1.5 \mathrm{cpd}, \mathrm{n}=20$ 282; $3.0 \mathrm{cpd}, \mathrm{n}=84 ; 6.0 \mathrm{cpd}, \mathrm{n}=88 ; 12 \mathrm{cpd}, \mathrm{n}=64 ; 18 \mathrm{cpd}$, $\mathrm{n}=124$ ) total cases to show a difference between groups. Therefore studies reporting results of small series with the Vistech or FACT may not be valid.

The drive to measure visual outcome of cataract and refractive surgery in the contrast domain, ${ }^{1-4} 6-8$ is not aided by these negative findings for the Vistech and FACT charts. In addition to possible reliability problems discussed above, the psychophysical design of other photographic patch tests of CS such as the CSV- $1000^{30}{ }^{31}$ with four spatial frequencies $(3,6$,
$12,18 \mathrm{cpd})$, minimum CS values of $(0.71,0.91,0.72,0.17 \mathrm{log}$ CS) and maximum values of $(2.08,2.29,1.99,1.55 \log C S)$ suggests it may also suffer from ceiling effects in near normal subjects and floor effects in cataract subjects, similar to the FACT. However, other tests, including low contrast visual acuity, Pelli-Robson and monitor based CS are more reliable and sensitive to the vision changes seen with cataract and refractive surgery, as well as being free from ceiling and floor effects. $^{45} 465667-70$

\section{ACKNOWLEDGMENTS}

This research was supported by a grant from the Vision Research Trust. The authors thank Stereo Optical Co for their loan of a FACT chart. We would also like to thank Ultralase, 77-85 Albion St, Leeds, LS1 5AP, UK for facilitating access to refractive surgery patients. NHMRC Sir Neil Hamilton Fairley Fellowship 007161 supports K Pesudovs.

\section{Authors' affiliations}

K Pesudovs, C A Hazel, D B Elliott, Department of Optometry, University of Bradford, Bradford, UK

R M L Doran, Department of Ophthalmology, Leeds General Infirmary, Leeds, West Yorkshire, UK

Correspondence to: Dr K Pesudovs, Department of Optometry, University of Bradford, Richmond Road, Bradford BD7 IDP, UK; konrad@pesudovs.com

Accepted for publication 15 May 2003

\section{REFERENCES}

1 Kohnen T. Measuring vision in refractive surgery. J Cataract Refract Surg 2001:27:1897-8.

2 Williams D, Yoon GY, Porter J, et al. Visual benefit of correcting higher order aberrations of the eye. J Refract Surg 2000;16:S554-9.

3 McLeod SD. Beyond snellen acuity: the assessment of visual function after refractive surgery. Arch Ophthalmol 2001;119:1371-3.

4 Lawless MA. Refining visual quality assessment in refractive surgery. J Cataract Refract Surg 1999;25:1031-2.

5 AHCPR Report: Cataract Management Guideline Panel. Cataract in Adults: Management of Real world Impairment. Rockville, MD: Department of Health and Human Services, Public Health Service, Agency for Health care Policy and research, AHCPR Pub. No. 93-0542, 1993. Clinical Practice Guideline Number 4.

6 Smith AF. Criteria for cataract surgery: the role of visual acuity and visual function. Br J Ophthalmol 1999;83:510-1.

7 AAO. Excimer laser photorefractive keratectomy (PRK) for myopia and astigmatism. American Academy of Ophthalmology. Ophthalmology 1999; 106:422-37.

8 Sugar A, Rapuano CJ, Culbertson WW, et al. Laser in situ keratomileusis for myopia and astigmatism: safety and efficacy: a report by the American Academy of Ophthalmology. Ophthalmology 2002;109:175-87.

9 Eiferman RA, O'Neill KP, Forgey DR, et al. Excimer laser photorefractive keratectomy for myopia: six month results. Refract Corneal Surg 1991;7:344-7.

10 Sher N, Chen V, Bowers R, et al. The use of a 193-nm excimer laser for myopic photokeratectomy in sighted eyes. A multicenter study. Arch Ophthamol 1991;109:1525-30. 
11 Sher N, Chen V, Bowers R, et al. Excimer laser photorefractive keratectomy in high myopia; A multicenter study. Arch Ophthamol 1992;110:935-43.

12 Wang Z, Chen J, Yang B. Comparison of laser in situ keratomileusis and photorefractive keratectomy to correct myopia from -1.25 to -6.00 diopters. $J$ Refract Surg 1997;13:528-34.

13 Haw WW, Manche EE. Excimer laser retreatment of residual myopia following photoastigmatic refractive keratectomy for compound myopic astigmatism. J Cataract Refract Surg 2000;26:660-7.

14 O'Brart DP, Stephenson CG, Baldwin $\mathrm{H}$, et al. Hyperopic photorefractive keratectomy with the erodible mask and axicon system: two year follow-up. $J$ Cataract Refract Surg 2000;26:524-35.

15 Sano Y, Carr JD, Takei K, et al. Videokeratography after excimer laser in situ keratomileusis for myopia. Ophthalmology 2000;107:674-84.

16 El Danasoury MA, El Maghraby A, Gamali TO. Comparison of iris-fixed Artisan lens implantation with excimer laser in situ keratomileusis in correcting myopia between -9.00 and -19.50 diopters: a randomized study. Ophthalmology 2002;109:955-64.

17 Jackson WB, Casson E, Hodge WG, et al. Laser vision correction for low hyperopia. An 18-month assessment of safety and efficacy. Ophthalmology 1998; 105:1727-38, discussion 37-8.

18 Holladay JT, Dudeja DR, Chang J. Functional vision and corneal changes after laser in situ keratomileusis determined by contrast sensitivity, glare testing, and corneal topography. J Cataract Refract Surg 1999;25:663-9.

19 Seiler T, Kaemmerer M, Mierdel P, et al. Ocular optical aberrations after photorefractive keratectomy for myopia and myopic astigmatism. Arch Ophthalmol 2000;118:17-21.

20 Mrochen M, Kaemmerer M, Seiler T. Clinical results of wavefront-guided laser in situ keratomileusis 3 months after surgery. J Cataract Refract Surg 2001:27:201-7.

21 Superstein R, Boyaner D, Overbury O, et al. Glare disability and contrast sensitivity before and after cataract surgery. I Cataract Refract Surg 1997:23:248-53.

22 Ellioft DB, Patla A, Bullimore MA. Improvements in clinical and functional vision and perceived visual disability after first and second eye cataract surgery. Br J Ophthalmol 1997;81:889-95.

23 Superstein R, Boyaner D, Overbury O. Functional complaints, visual acuity, spatial contrast sensitivity, and glare disability in preoperative and postoperative cataract patients. J Cataract Refract Surg 1999;25:575-81

24 Armbrecht AM, Findlay C, Kaushal S, et al. Is cataract surgery justified in patients with age related macular degeneration? A visual function and quality of life assessment. Br J Ophthalmol 2000;84:1343-8.

25 Elliott DB, Patla AE, Furniss $M$, et al. Improvements in clinical and functiona vision and quality of life after second eye cataract surgery. Optom Vis Sci 2000;77:13-24

26 Mallah MK, Hart PM, McClure M, et al. Improvements in measures of vision and self-reported visual function after cataract extraction in patients with latestage age-related maculopathy. Optom Vis Sci 2001;78:683-8.

27 Ginsburg AP. A new contrast sensitivity vision test chart. Am J Optom Physiol Opt 1984;61:403-7

28 Corwin TR, Richman JE. Three clinical tests of the spatial contrast sensitivity function: a comparison. Am J Optom Physiol Opt 1986:63:413-8.

29 Ginsburg AP, Waring GO 3rd, Steinberg EB, et al. ontrast sensitivity under photopic conditions in the Prospective Evaluation of Radial Keratotomy (PERK) Study. Refract Corneal Surg 1990;6:82-91.

30 Pomerance GN, Evans DW. Test-retest reliability of the CSV-1000 contrast test and its relationship to glaucoma therapy. Invest Ophthalmol Vis Sci 1994;35:3357-61.

31 Arend O, Remky R, Evans D, et al. Contrast sensitivity loss is coupled with capillary dropout in patients with diabetes. Invest Ophthalmol Vis Sci 1997:38:1819-24.

32 Pelli DG, Robson JG, Wilkins AJ. The design of a new letter chart for measuring contrast sensitivity. Clin Vis Sci 1988;2:187-99.

33 Chylack LT Jr, Jakubicz G, Rosner B, et al. Contrast sensitivity and visual acuity in patients with early cataracts. J Cataract Refract Surg 1993;19:399-404.

34 de Waard PW, IJspeert JK, van den Berg TJ, et al. Intraocular light scattering in age-related cataracts. Invest Ophthalmol Vis Sci 1992;33:618-25.

35 Lasa MS, Datiles MB 3rd, Podgor MJ, et al. ontrast and glare sensitivity. Association with the type and severity of the cataract. Ophthalmology 1992:99:1045-9.

36 Pfoff DS, Werner JS. Effect of cataract surgery on contrast sensitivity and glare in patients with 20/50 or better Snellen acuity. I Cataract Refract Surg 1994:20:620-5

37 Rouhiainen P, Rouhiainen H, Salonen JT. Contrast sensitivity in different types of early lens opacities. Acta Ophthalmol Scand 1996:74:379-83.

38 Ghaith AA, Daniel J, Stulting RD, et al. Contrast sensitivity and glare disability after radial keratotomy and photorefractive keratectomy. Arch Ophthalmol 1998;116:12-8.

39 Niesen U, Businger U, Hartmann $P$, et al. Glare sensitivity and visual acuity after excimer laser photorefractive keratectomy for myopia. Br J Ophthalmol 1997;81:136-40
40 Tomidokoro A, Soya K, Miyata K, et al. Corneal irregular astigmatism and contrast sensitivity affer photorefractive keratectomy. Ophthalmology 2001;108:2209-12.

41 Vetrugno M, Quaranta GM, Maino A, et al. Contrast sensitivity measured by 2 methods after photorefractive keratectomy. I Cataract Refract Surg 2000;26:847-52.

42 Kennedy RS, Dunlap WP. Assessment of the Vistech contrast sensitivity test for repeated measures applications. Optom Vis Sci 1990;67:248-51.

43 Long GM, Tuck JP. Reliabilities of alternate measures of contrast sensitivity functions. Am J Optom Physiol Opt 1988;65:37-48.

44 Reeves BC, Wood JM, Hill AR. Vistech VCTS 6500 charts-within- and between-session reliability, Optom Vis Sci 1991:68:728-37.

45 Rubin GS. Reliability and sensitivity of clinical contrast sensitivity tests. Clin Vis Sci 1988;2:169-77.

46 Elliott DB, Bullimore MA. Assessing the reliability, discriminative ability, and validity of disability glare tests. Invest Ophthalmol Vis Sci 1993;34:108-19.

47 Ginsburg AP. Next generation contrast sensitivity testing. In: Rosenthal B, Cole R, eds. Functional Assessment of Low Vision. St Lovis: Mosby Year Book Inc, 1996:77-88.

48 Kaupp SE, Schallhorn SC, Lewis RB, et al. Recovery of photopic contrast sensitivity after PRK. Invest Ophthalmol Vis Sci 1998;39:S465.

49 Wachler BS, Durrie DS, Assil KK, et al. Role of clearance and treatment zones in contrast sensitivity: significance in refractive surgery. $J$ Cataract Refract Surg 1999;25:16-23.

50 Montes-Mico R, Charman WN. Choice of spatial frequency for contrast sensitivity evaluation after corneal refractive surgery. I Refract Surg 2001;17:646-51

51 Montes-Mico R, Charman WN. Mesopic contrast sensitivity function after excimer laser photorefractive keratectomy. J Refract Surg 2002;18:9-13.

52 Yan Z, Hu J, Gu X, et al. Contrast sensitivity function in myopic LASIK. Zhonghua Yan Ke Za Zhi 2002;38:677-9.

53 Bland JM, Altman DG. Statistical methods for assessing agreement between two methods of clinical measurement. Lancet 1986:307-10.

54 Ambrosio G, Cennamo G, De Marco R, et al. Visual function before and after photorefractive keratectomy for myopia. J Refract Corneal Surg 1994:10:129-36

55 Elliott DB, Whitaker D. Clinical contrast sensitivity chart evaluation. Ophthalmic Physiol Opt 1992;12:275-80

56 Arditi A, Cagenello R. On the statistical reliability of letter-chart visual acuity measurements. Invest Ophthal Vis Sci 1993;34:120-9.

57 Elliott DB, Bullimore MA, Bailey IL. Improving the reliability of the Pelli-Robson contrast sensitivity test. Clin Vis Sci 1991;6:471-5.

58 Frost NA, Sparrow JM. Use of vision tests in clinical decision making about cataract surgery: results of a national survey. $\mathrm{Br} J$ Ophthalmol 2000;84:432-4.

59 King-Smith PE, Grigsby SS, Vingrys AJ, et al. Efficient and unbiased modifications of the QUEST threshold method: theory, simulations, experimental evaluation and practical implementation. Vision Res 1994:34:885-912.

60 McKee SP, Klein SA, Teller DY. Statistical properties of forced-choice psychometric functions: implications of probit analysis. Percept Psychophys 1985:37:286-98.

61 Piebenga LW, Matta CS, Deitz MR, et al. Excimer photorefractive keratectomy for myopia. Ophthalmology 1993;100:1335-45.

62 Dutt S, Steinert RF, Raizman MB, et al. One year results excimer laser photorefractive keratectomy for low to moderate myopia. Arch Ophthalmol 1994:112:1427-36

63 Maloney RK, Chan W-K, Steinert R, et al. A multicentre trial of photorefractive keratectomy for residual myopia after previous ocular surgery. Ophthalmology 1995;102:1042-53.

64 Hersh PS, Stulting RD, Steinert RF, et al. Results of phase III excimer laser photorefractive keratectomy for myopia. The Summit PRK Study Group. Ophthalmology 1997; 104:1535-53.

65 Mutyala S, McDonald MB, Scheinblum KA, et al. Contrast sensitivity evaluation after laser in situ keratomileusis. Ophthalmology 2000;107:1864-7.

66 Perez-Santonja JJ, Sakla HF, Alio JL. Contrast sensitivity after laser in situ keratomileusis. J Cataract Refract Surg 1998:24:183-9.

67 Rubin GS, Adamsons IA, Stark WJ. Comparison of acuity, contrast sensitivity, and disability glare before and affer cataract surgery. Arch Ophthalmol 1993;111:56-61.

68 Pesudovs K, Coster DJ. Assessment of visual function in cataract patients with a mean visual acuity of 6/9. Aust NZ J Ophthalmol 1996;24:5-9.

69 Bullimore MA, Olson MD, Maloney RK. Visual performance after photorefractive keratectomy with a 6-mm ablation zone. Am J Ophthalmol 1999:128:1-7.

70 Applegate RA, Hilmantel G, Howland HC, et al. Corneal first surface optical aberrations and visual performance. J Refract Surg 2000;16:507-14. 